\title{
SATISFAÇÃO DA PUÉRPERA COM OS CUIDADOS DE ENFERMAGEM RECEBIDOS EM UM ALOJAMENTO CONJUNTO ${ }^{1}$
}

\author{
Natália Gabriela Odinino², Edinêis de Brito Guirardello ${ }^{3}$
}

\footnotetext{
${ }^{1}$ Extraído do Trabalho de Iniciação Científica - Satisfação da puérpera em uma unidade de alojamento conjunto, 2007. Financiado pela Fundação de Amparo à Pesquisa do Estado de São Paulo, Processo no 06/ 61185-4.

2 Enfermeira da Prefeitura Municipal de Cosmópolis - Unidade de Saúde da Família, Vila Cosmos. Cosmópolis. São Paulo, Brasil. E-mail: natgabizinha@yahoo.com.br

${ }^{3}$ Livre Docente do Departamento de Enfermagem da Faculdade de Ciências Médicas da Universidade Estadual de Campinas. São Paulo, Brasil. E-mail: guirar@fcm.unicamp.br
}

RESUMO: Estudo descritivo que objetivou avaliar a satisfação das puérperas com os cuidados de enfermagem recebidos em um alojamento conjunto e verificar se a mesma difere com relação a algumas variáveis demográficas e obstétricas. Para a coleta de dados utilizou-se o Instrumento de Satisfação do Paciente e a ficha sócio-demográfica e obstétrica. Participaram 187 puérperas com idade média de 26,1 anos. Dessas, 27,8\% eram primíparas, 34,8\% secundíparas e 37,4\% multíparas, com predomínio de parto vaginal. As puérperas relataram satisfação com os cuidados recebidos para todos os domínios do instrumento e àquelas com três ou mais gestações relataram maior nível de satisfação para o domínio educacional em relação àquelas com duas gestações. As mulheres com parto vaginal também estavam mais satisfeitas quanto aos domínios técnico-profissional e educacional em relação às mulheres com parto cesáreo. Conhecer o nível de satisfação das puérperas com os cuidados de enfermagem possibilita ao enfermeiro planejar e implementar uma assistência com qualidade.

DESCRITORES: Período pós-parto. Satisfação do paciente. Cuidados de enfermagem.

\section{PUERPERAS`S SATISFACTION WITH NURSING CARE RECEIVED IN A ROOMING-IN CARE}

\begin{abstract}
This is a descriptive study with the objective to assess the level of satisfaction of puerperas with the nursing care provided in rooming-in settings and to verify whether this satisfaction differ regarding some demographic and obstetric variables. For data collection, the Patient Satisfaction Instrument and the demographic and obstetric characterization form were used. Participants were 187 puerperas with average age of 26.1 years. From this sample, $27.8 \%$ were primiparous, 34.8\% secundiparous and $37.4 \%$ multiparous, with a predominance of vaginal delivery. The puerperas reported satisfaction with the care received for all domains of the instrument and the one with three or more pregnancies reported greater satisfaction level for the educational domain than those with two pregnancies. The puerperas with vaginal delivery were also more satisfied in relation to technical-professional care and educational domains than puerperas with cesarean births. Knowing the puerperas`satisfaction with nursing care will help nurses to plan and implement an assistance with quality.
\end{abstract}

DESCRIPTORS: Postpartum period. Patient satisfaction. Nursing care.

\section{SATISFACCIÓN DE LAS PUÉRPERAS CON LOS CUIDADOS DE ENFERMERÍA RECIBIDOS EN UN ALOJAMIENTO CONJUNTO}

RESUMEN: Estudio descriptivo que tiene el objetivo de evaluar el nivel de satisfacción de las puérperas a los cuidados de enfermería recibidos en un alojamiento conjunto y verificar si esta satisfacción se diferencia según variables demográficas y obstétricas. Para recopilar los datos se utilizó el Instrumento de Satisfacción del Paciente y un cuestionario de caracterización sociodemográfica y clínica. Participaron 187 puérperas con edad promedio de 26,1 años. En esta muestra, 27,8\% eran primíparas, 34,8\% secundíparas y 37,4\% multíparas, con predominio del parto vaginal. Las puérperas declararon satisfacción con la atención recibida en todos los dominios del instrumento y las que tienen tres o más embarazos declararon mayor nivel de satisfacción en el área educacional comparada con aquellas con dos embarazos. Las puérperas con parto vaginal estuvieron también más satisfechas con respecto al área técnico profesional y educacional en relación a las puérperas con cesárea. El conocimiento del grado de satisfacción de las puérperas con el cuidado de enfermería permite planificar e implementar una asistencia con calidad.

DESCRIPTORES: Periodo de posparto. Satisfacción del paciente. Atención de enfermería. 


\section{INTRODUÇÃO}

Com o processo de institucionalização do parto, a mulher está sujeita à hospitalização para receber assistência durante o processo de parturição. A hospitalização pode constituir um fator gerador de estresse, pois além da separação da família e do seu ambiente domiciliar, a mulher irá deparar-se com diferentes normas e rotinas próprias do ambiente hospitalar, que se acrescem à ansiedade diante das mudanças exigidas pelo status da maternidade.

Durante a fase de recuperação, após o parto, a puérpera apresenta momentos de dependência dos cuidados de enfermagem oferecidos a ela e ao bebê; tais momentos são decisivos para que o enfermeiro possa direcionar um cuidado que venha a atender às necessidades de ambos. ${ }^{1}$ Tradicionalmente, supunha-se que para se ter uma boa qualidade de assistência à saúde dever-se-ia conhecer as necessidades da clientela, com base em padrões profissionais e recursos financeiros. Hoje, porém, num ambiente cada vez mais competitivo de assistência à saúde, na valorização do atendimento aos clientes, os gerentes estão mais atentos e preocupados em avaliar a satisfação do paciente em relação ao cuidado recebido. ${ }^{2}$

Uma boa qualidade do cuidado, sob a perspectiva das gestantes, inclui a cortesia e a competência dos profissionais. A percepção das mulheres que usam os serviços de uma maternidade contribui para melhorar a sua satisfação, já que pode identificar os pontos positivos e negativos em relação ao cuidado recebido. ${ }^{3}$ Alguns autores ${ }^{4}$ enfatizam que a maneira como a puérpera percebe e lida com a experiência do parto e nascimento de seu filho é um fator que também interfere na sua satisfação.

Existem diferentes abordagens conceituais sobre a satisfação do paciente. Essa pode ser definida como as avaliações positivas individuais de distintas dimensões do cuidado à saúde ${ }^{5}$; enquanto para outros autores é compreendida como sendo a expectativa do paciente quanto ao cuidado de enfermagem contraposta à sua percepção quanto ao cuidado recebido. ${ }^{6-7}$

São muitas as definições encontradas na literatura sobre a percepção do paciente quanto aos cuidados de enfermagem. Independentemente dessas variações, geralmente os pacientes consideram-se satisfeitos quando suas necessidades são atendidas, o tratamento que recebem é agradável e a equipe importa-se, é atenciosa e competente. ${ }^{8}$
Nesse caso, os pacientes satisfeitos tendem a retornar ao serviço ou recomendá-lo para outra pessoa. Puérperas satisfeitas com o atendimento no hospital provavelmente são aquelas que estão mais satisfeitas com os cuidados de enfermagem; dessa forma, recomendariam os serviços da instituição para uma amiga. ${ }^{9}$

O Alojamento Conjunto (AC) é um sistema hospitalar em que o recém-nascido sadio permanece com a mãe logo após o nascimento, 24 horas por dia, até a alta hospitalar. Tal estrutura possibilita que todos os cuidados assistenciais sejam prestados ao binômio mãe e filho. Algumas das vantagens do AC são: favorecer o aleitamento materno em livre demanda e sua manutenção por tempo prolongado, fortalecer o vínculo entre mãe e filho e oferecer condições para que a equipe de enfermagem possa proporcionar orientações à puérpera por meio de demonstrações práticas dos cuidados indispensáveis ao recém-nascido. ${ }^{10}$

A experiência de internação no $\mathrm{AC}$, para as puérperas, pode fazer emergir sentimentos de medo, sofrimento e abandono. Contudo, ao perceber que há alguém para ajudá-las, sentem-se mais seguras em relação ao atendimento de suas necessidades. ${ }^{11} \mathrm{O}$ enfermeiro e o técnico de enfermagem são os profissionais que permanecem por mais tempo ao lado da mãe e do recém-nascido quando em AC, responsabilizando-se pela assistência ininterrupta do binômio até o momento da alta. Se a puérpera estiver satisfeita com a assistência, a formação do vínculo entre profissional e cliente poderá ser mais efetiva. Desta forma, os objetivos do AC poderão ser alcançados, em benefício da mãe e do bebê.

Atualmente, para mensurar a satisfação do paciente com os cuidados de enfermagem, os enfermeiros devem considerar a maneira como a enfermagem é definida e organizada atualmente, para então tentar desenvolver e implementar instrumentos válidos e confiáveis que objetivam avaliar a satisfação com os cuidados de enfermagem. ${ }^{2}$

Nas últimas décadas, estudos têm sido desenvolvidos para propor métodos que visem avaliar a satisfação do paciente com os cuidados de enfermagem. Dentre eles destacam-se o Patient Satisfaction Instrument (PSI) ${ }^{12}$, La Monica Oberst Patient Satisfaction Scale (LOPSS) ${ }^{7}$, e a Newcastle Satisfaction with Nursing Scales (NSNS). ${ }^{9}$ Entretanto, poucos estudos contemplam especificamente a avaliação da satisfação da puérpera com relação aos cuidados de enfermagem e esses não estão disponíveis para uso em nosso idioma. 
O Patient Satisfaction Instrument foi validado para a cultura brasileira, ${ }^{12-13}$ recebendo nome de Instrumento de Satisfação do Paciente (ISP). Embora não seja específico para o puerpério, pode ser útil para avaliar a satisfação da puérpera com os cuidados de enfermagem, em uma unidade de AC, contribuindo assim para reavaliação do processo de trabalho e para a sensibilização da equipe no atendimento das necessidades da clientela.

\section{OBJETIVOS}

O presente estudo teve como objetivo principal avaliar a satisfação de puérperas com os cuidados de enfermagem recebidos em um Alojamento Conjunto e, como objetivo secundário, verificar se o nível de satisfação das puérperas difere em relação a variáveis como: idade, nível de escolaridade, número de gestações, tipo de parto, situação conjugal e experiência prévia de hospitalização.

\section{MÉTODOS}

Trata-se de um estudo descritivo, de abordagem quantitativa, realizado no AC do Hospital da Mulher Prof. Dr. José Aristodemo Pinotti - Centro de Atenção Integral à Saúde da Mulher - (CAISM), um hospital de ensino localizado no interior do Estado de São Paulo, que atende exclusivamente à clientela do Sistema Único de Saúde (SUS). O hospital possui 139 leitos. Destes, o AC tem capacidade de atendimento para 24 binômios.

O tempo de permanência de mãe e filho no AC do hospital varia de 48 horas, para as mulheres que tiveram parto vaginal a 72 horas, paras a mulheres que tiveram o parto cirúrgico, desconsideradas as possíveis intercorrências com a mãe ou o bebê.

Para o cálculo da amostra, realizou-se previamente um estudo piloto com 30 puérperas, aplicando o ISP e preenchendo a ficha de caracterização dos sujeitos. O estudo piloto possibilitou estimar o tamanho da amostra em 187 puérperas, fixando o nível de significância em 5\%. Como as entrevistas do pré-teste não resultaram em alteração na forma de aplicação do ISP, foram consideradas na amostra final.

Como critério de inclusão no estudo, considerou-se: puérperas em alta hospitalar com idades igual ou superior a 18 anos e que concordaram em participar do estudo. Foram excluídas da amostra as puérperas com gravidez múltipla que tivessem um dos bebês internados na Unidade de Terapia Intensiva Neonatal (UTIN). Desta forma, garantiu-se que todos os sujeitos expressassem sua satisfação com os cuidados de enfermagem especificamente recebidos no AC.

As puérperas foram convidadas a participar do estudo, informadas sobre seu propósito, modo de participação e garantia de anonimato na divulgação dos resultados e, após concordarem, foram solicitadas a assinar o Termo de Consentimento Livre e Esclarecido. A coleta individual de dados foi realizada durante os meses de abril a julho de 2007 por uma das pesquisadoras, por meio de entrevista, nas dependências da unidade do AC.

Para a coleta de dados que permitissem mensurar a satisfação com os cuidados de enfermagem, utilizou-se ISP, validado para a cultura brasileira. ${ }^{13} \mathrm{O}$ ISP é um instrumento constituído de 25 itens, agrupados em três domínios: Profissional, Educacional e Confiança. No domínio Profissional, composto de sete itens, há afirmativas que remetem à habilidade técnica do enfermeiro, sua destreza e competência. O domínio Educacional dispõe também de sete itens e aborda a clareza na comunicação e nas orientações ao paciente. O domínio Confiança contém 11 situações sobre relacionamento interpessoal entre enfermeiro e paciente e diz respeito à atenção cuidadosa, ao ouvir, à empatia. Estão representados numa escala de medida do tipo Likert, com cinco alternativas de respostas, variando de "concordo totalmente" para "discordo totalmente". Desta forma, quanto maior a pontuação, maior o nível de satisfação.

Também foi utilizada uma ficha de identificação da puérpera, contemplando os dados sóciodemográficos e obstétricos: data de admissão, idade, profissão/ocupação, situação conjugal, nível de escolaridade, renda mensal familiar, número de gestações, tipo de parto e experiência prévia de hospitalização. No que diz respeito à variável "tipo de parto", essa foi dividida em duas categorias: parto vaginal (o que inclui parto normal, fórceps e parto de cócoras) e parto cesáreo.

O estudo obteve parecer favorável do Comitê de Ética em Pesquisa da instituição (Processo $n^{\circ}$ 054/2007). Todos os aspectos que envolvem a pesquisa estão de acordo com a Resolução n 196/96 do Conselho Nacional de Saúde.

Para análise estatística dos dados utilizouse o programa computacional SAS System for Windows (Statistical Analysis System), versão 8.02. Para descrever o perfil da amostra segundo as diversas variáveis em estudo, foram feitas tabelas 
de frequência das variáveis categóricas e estatísticas descritivas (média, desvio padrão, mediana, mínimo e máximo) das variáveis contínuas.

Para comparar o nível de satisfação das puérperas em relação às variáveis categóricas utilizou-se a Análise de variância (ANOVA) com transformação Rank, em virtude da não existência de normalidade dos dados, para diminuir sua assimetria e variabilidade.

Para verificar a existência de correlação entre as variáveis, calculou-se o coeficiente de correlação de Pearson, cujos valores demonstram que, quanto mais próximo de zero, menos correlacionadas são as variáveis, e quanto mais próximo de 1 ou -1 , mais correlacionadas elas são. ${ }^{14}$

Para avaliar o nível de consistência interna do ISP, calculou-se o coeficiente Alfa de Cronbach, usado para verificar a homogeneidade ou acurácia dos itens do instrumento. Como regra geral, a acurácia não deve ser menor que 0,80 se a escala for amplamente utilizada, porém, valores acima de 0,60 já indicam consistência. ${ }^{15} \mathrm{O}$ nível de significância adotado para os testes estatísticos foi de $5 \%$, ou seja, $\mathrm{p}<0,05$.

\section{RESULTADOS}

Participaram do estudo 187 puérperas, sendo que a maioria $(87,2 \%)$ estava na faixa etária entre 18 a 32 anos (idade média 26,1 anos, Min=18; Max=44). A maioria (57,2\%) relatou união estável. Quanto ao nível de escolaridade, têm-se 34,8\% das puérperas com ensino fundamental incompleto e $30,5 \%$ com ensino médio completo. A renda mensal relatada foi de um a dois salários mínimos para a maioria $(59,4 \%)$. No que se refere à profissão, $49,2 \%$ relataram atividades do lar e 17,7\% atividades domésticas e serviços gerais (Tabela 1).

Em relação aos dados obstétricos, 37,4\% relataram três ou mais gestações, $34,8 \%$ duas e $27,8 \%$ uma gestação. Mais da metade da amostra $(55,6 \%)$ teve o parto por via vaginal, enquanto que a taxa de parto cesáreo na amostra foi de 44,4\%. Destacase que, dos 104 partos vaginais, 11 deles usaram fórceps e houve um parto de cócoras. O tempo de internação da maioria $(64,2 \%)$ das puérperas no momento da entrevista foi de dois dias, com uma média de 2,46 dias e a maioria $(77 \%)$ relatou não ter experiência prévia de hospitalização na referida unidade (Tabela 1).

Ao correlacionar as variáveis, constatou-se diferenças para o nível de escolaridade e número de gestações, ou seja, as mulheres com nível fudamental possuem maior número de filhos quando comparadas às mulheres com nível médio $(p=0,0001)$.

Tabela 1 - Distribuição da frequência e porcentagem das puérperas, segundo variáveis sócio-demográficas e obstétricas. Campinas - SP, 2007.

\begin{tabular}{|c|c|c|}
\hline Características & $\begin{array}{c}\text { Distribui- } \\
\text { ção da } \\
\text { amostra } \\
\text { (n) }\end{array}$ & $\%$ \\
\hline \multicolumn{3}{|l|}{ Idade (anos) } \\
\hline 18 a 24 & 80 & 42,8 \\
\hline 25 a 32 & 83 & 44,4 \\
\hline 33 ou mais & 24 & 12,8 \\
\hline \multicolumn{3}{|l|}{ Renda (Salário mínimo) } \\
\hline Não informado & 13 & 7,0 \\
\hline 1 a 2 & 111 & 59,4 \\
\hline 3 a 4 & 29 & 15,5 \\
\hline 5 ou mais & 34 & 18,2 \\
\hline \multicolumn{3}{|l|}{ Estado civil } \\
\hline Solteira & 25 & 13,4 \\
\hline União estável & 107 & 57,2 \\
\hline Casada & 53 & 28,3 \\
\hline Outros & 2 & 1,1 \\
\hline \multicolumn{3}{|l|}{ Escolaridade } \\
\hline Analfabeta & 1 & 0,5 \\
\hline Ensino fundamental incompleto & 65 & 34,8 \\
\hline Ensino fundamental completo & 24 & 12,8 \\
\hline Ensino médio incompleto & 27 & 14,4 \\
\hline Ensino médio completo & 57 & 30,5 \\
\hline Ensino superior incompleto e completo & 13 & 7,0 \\
\hline \multicolumn{3}{|l|}{ Profissão/ocupação } \\
\hline Do lar & 92 & 49,2 \\
\hline Doméstica/Auxiliar de limpeza/Cozinha & 41 & 22,0 \\
\hline Auxiliar administrativa/Vendedora & 22 & 11,8 \\
\hline Outros & 32 & 17,0 \\
\hline \multicolumn{3}{|l|}{ Tempo de internação (dias) } \\
\hline Um & 10 & 5,3 \\
\hline Dois & 120 & 64,2 \\
\hline Três & 56 & 29,9 \\
\hline Quatro ou mais & 15 & 8,0 \\
\hline \multicolumn{3}{|l|}{ Número gestações } \\
\hline Uma & 52 & 27,8 \\
\hline Duas & 65 & 34,8 \\
\hline Três ou mais & 70 & 37,4 \\
\hline \multicolumn{3}{|l|}{ Tipo de Parto } \\
\hline Vaginal† & 104 & 55,6 \\
\hline Cesárea & 83 & 44,4 \\
\hline \multicolumn{3}{|l|}{ Hospitalização prévia } \\
\hline Sim & 43 & 23,0 \\
\hline Não & 144 & 77,0 \\
\hline
\end{tabular}

Salário mínimo nacional de R\$ 380,00 e cotação do dólar igual a aproximadamente $\mathrm{R} \$ 2,00$ no primeiro semestre de 2007. $†$ Normal, normal com fórceps e cócoras. 
Todas as puérperas relataram alto nível de satisfação com os cuidados de enfermagem para todos os itens do ISP, cujas médias variaram de 3,2 a 4,0 pontos, numa escala que varia de um (1) a cinco
(5) pontos. Destaca-se que das três situações com maiores médias julgadas pelas puérperas, duas estão relacionadas ao domínio técnico-profissional e uma ao domínio confiança (Tabela 2).

Tabela 2 - Médias e desvios-padrão de satisfação das puérperas por itens do ISP. Campinas - SP, 2007.

\begin{tabular}{|c|c|c|c|}
\hline Itens* & Instrumento de satisfação do paciente & Média & DP \\
\hline 25 & O(A) enfermeiro(a) é habilidoso(a) ao auxiliar o médico nos procedimentos & 4,0 & 0,40 \\
\hline 3 & $O(A)$ enfermeiro(a) é uma pessoa agradável de se ter por perto & 4,0 & 0,42 \\
\hline 12 & O(A) enfermeiro(a) faz questão de me mostrar como seguir as orientações médicas & 4,0 & 0,45 \\
\hline 23 & Só de conversar com o enfermeiro(a) já me sinto melhor & 3,9 & 0,52 \\
\hline 15 & $\mathrm{O}(\mathrm{A})$ enfermeiro(a) dá bons conselhos & 3,9 & 0,57 \\
\hline 20 & O(A) enfermeiro(a) não faz corretamente o seu trabalho & 3,9 & 0,58 \\
\hline 7 & O(A) enfermeiro(a) explica as coisas em uma linguagem simples & 3,9 & 0,61 \\
\hline 22 & Eu estou cansado(a) do(a) enfermeiro(a) falar comigo como se eu fosse uma pessoa inferior & 3,9 & 0,63 \\
\hline 21 & O(A) enfermeiro(a) fornece as orientações na velocidade correta & 3,8 & 0,66 \\
\hline 4 & A gente se sente à vontade para fazer perguntas ao enfermeiro(a) & 3,8 & 0,70 \\
\hline 24 & $\begin{array}{l}\text { O(A) enfermeiro(a) sempre dá explicações completas e suficientes do por que os exames } \\
\text { foram solicitados }\end{array}$ & 3,8 & 0,71 \\
\hline 18 & $\mathrm{O}(\mathrm{A})$ enfermeiro(a) é muito lento para fazer as coisas para mim & 3,7 & 0,72 \\
\hline 19 & $O(A)$ enfermeiro(a) não tem paciência suficiente & 3,7 & 0,72 \\
\hline 14 & O(A) enfermeiro(a) é compreensivo(a) ao ouvir os problemas do paciente & 3,7 & 0,75 \\
\hline 13 & O(A) enfermeiro(a) está sempre muito desorganizado para aparentar calma & 3,7 & 0,77 \\
\hline 16 & $\mathrm{O}(\mathrm{A})$ enfermeiro(a) realmente sabe do que está falando & 3,7 & 0,77 \\
\hline 8 & $\begin{array}{l}\mathrm{O}(\mathrm{A}) \text { enfermeiro(a) faz muitas perguntas, mas quando ele (a) recebe a resposta, parece não } \\
\text { fazer nada a respeito }\end{array}$ & 3,6 & 0,82 \\
\hline 2 & $\begin{array}{l}\text { O(A) enfermeiro(a) muitas vezes acha que você não é capaz de entender a explicação médica } \\
\text { sobre sua doença, então ele simplesmente não se preocupa em explicar }\end{array}$ & 3,6 & 0,85 \\
\hline 17 & É sempre fácil entender o que o (a) enfermeiro (a)está dizendo & 3,6 & 0,85 \\
\hline 6 & O(A) enfermeiro(a) é uma pessoa que consegue entender como eu me sinto & 3,6 & 0,90 \\
\hline 10 & $\mathrm{O}(\mathrm{A})$ enfermeiro(a) está muito ocupado (a) no posto para perder tempo conversando comigo & 3,4 & 0,92 \\
\hline 5 & O(A) enfermeiro(a) deveria ser mais amigável do que ele ou ela é & 3,4 & 0,94 \\
\hline 9 & Quando eu preciso conversar com alguém, eu posso contar meus problemas ao enfermeiro(a) & 3,2 & 1,00 \\
\hline 11 & Eu gostaria que o enfermeiro(a) me desse mais informações sobre os resultados do meu exame & 3,2 & 1,01 \\
\hline 1 & $O(A)$ enfermeiro(a) deveria ser mais atencioso (a) do que ele ou ela é & 3,2 & 1,02 \\
\hline
\end{tabular}

Ao avaliar a média resultante das pontuações do ISP, obteve-se uma média de 3,7 para o total de itens, uma média de 3,8 para o domínio técnico- profissional, e 3,6 para o domínio educacional e confiança (Tabela 3).

Tabela 3 - Médias das pontuações para o total de itens e domínios do ISP. Campinas - SP, 2007.

\begin{tabular}{lccccc}
\hline Domínios & Média & DP & Mínimo & Mediana & Máximo \\
\hline Educacional & 3,6 & 0,45 & 1,7 & 3,7 & 4,4 \\
Confiança & 3,6 & 0,44 & 2,2 & 3,8 & 4,5 \\
Profissional & 3,8 & 0,37 & 2,3 & 4,0 & 4,9 \\
Total de itens & 3,7 & 0,38 & 2,4 & 3,8 & 4,4 \\
\hline
\end{tabular}


A consistência interna do ISP foi avaliada por meio do coeficiente alfa de Cronbach que resultou em consistência satisfatória para o total de itens do ISP $(\alpha=0,87)$ e para os domínios: confiança $(\alpha=$ $0,78)$; técnico-profissional $(\alpha=0,70)$ e educacional $(\alpha=0,66)$.

Em seguida, foi avaliado se o nível de satisfação das puérperas diferia em relação às variáveis. Foi possível verificar que as mulheres com três ou mais gestações relataram maior nível de satisfação para o domínio educacional em relação àquelas com duas gestações $(p=0,036)$. Quanto ao tipo de parto, as puérperas que realizaram parto vaginal relataram maior nível de satisfação para as situações relacionadas tanto aos domínios técnico-profissional $(p=0,026)$ como o educacional $(p=0,025)$, se comparadas às mulheres que realizaram parto cesárea.

\section{DISCUSSÃO}

Trata-se de um grupo de puérperas jovens, com nível de escolaridade que se concentra entre o ensino fundamental incompleto e médio completo, com baixa renda salarial mensal - que pode ser consequência da própria profissão/ocupação que usualmente está relacionada ao salário mínimo. A baixa escolaridade entre as mulheres no presente estudo retrata a situação educacional das jovens brasileiras que é considerada precária, em que aproximadamente $10 \%$ das mulheres fazem curso superior. A renda mensal também revela um perfil familiar com pequeno poder aquisitivo, o que equivale ao perfil da maioria dos brasileiros. ${ }^{16}$

Convém destacar que apesar da faixa etária jovem, o número de mulheres com mais de três gestações é alto. Estudos apontam que um terço das mulheres na faixa etária de 15 a 24 anos já são mães, e 13,8\% delas têm o segundo filho na faixa etária de 20 a 24 anos, o que sugere o início precoce da maternidade em nosso meio. ${ }^{16} \mathrm{~A}$ atividade do lar foi a principal ocupação apontada por elas, seguida de empregada doméstica ou auxiliar de limpeza, sendo esse dado semelhante a um estudo que apontou que das $60 \%$ das mulheres que referem uma atividade fora do lar, um terço delas exercem atividade de empregada doméstica. ${ }^{16}$ Nota-se um perfil de mulheres em que a maioria $(57,2 \%)$ não é casada, mas relata união estável. Desde 1986 tem havido decréscimo de registro de matrimônios legais, assim como houve o aumento das separações conjugais. ${ }^{16}$

Destaca-se que, para a maioria das puérperas, no momento da entrevista, o tempo de internação foi superior a dois dias e apenas 10 puérperas foram abordadas num tempo inferior a dois dias, mas já estavam com alta prevista. O tempo de permanência na unidade de AC de pelo menos dois dias tem sido considerado um tempo adequado para que a puérpera possa experienciar as atividades de enfermagem bem como avaliar a sua importância. ${ }^{17}$ Essa necessidade é reforçada pelos enfermeiros quando apontam que um período reduzido de permanência no hospital e a alta rotatividade de pacientes são fatores que dificultam o provimento de informações e suporte às puérperas. ${ }^{18}$

Embora a taxa de parto cesáreo tenha sido menor em relação à taxa do parto vaginal, 44,4\% é um número considerado elevado e uma das possíveis causas é o fato de ser um hospital de ensino de referência no atendimento a gestação de alto risco. Apesar disso, o número de cesáreas foi inferior ao encontrado em um estudo ${ }^{19} \mathrm{em}$ que os autores justificaram que o número elevado de cesáreas pode ser devido às condições perinatais de risco que a instituição atende. A taxa de parto cesáreo no Brasil é de 39\%, índice considerado alto, quando contraposto a $15 \%$ como preconiza a Organização Mundial da Saúde. ${ }^{20}$

De um modo geral, a amostra foi homogênea; destaca-se apenas a associação entre escolaridade e número de gestações que foi diferente entre as puérperas, mostrando que mulheres com ensino fundamental apresentaram maior número de gestação em relação a mulheres com ensino médio. Tais achados corroboram com os dados do Instituto Brasileiro de Geografia e Estatística (IBGE). ${ }^{16}$

Com relação ao objetivo principal do estudo, que foi avaliar a satisfação da puérpera no AC, foi possível verificar que as puérperas relataram satisfação com os cuidados de enfermagem para todos os itens do ISP, sendo a média de 3,7 pontos numa escala que varia de um (1) a cinco (5) pontos. As situações com maiores médias foram as relacionadas ao domínio técnico-profissional, seguida do domínio confiança, as quais foram: "O(A) enfermeiro(a) é habilidoso(a) ao auxiliar o médico nos procedimentos"; “O(A) enfermeiro(a) faz questão de me mostrar como seguir as orientações médicas" e "O(A) enfermeiro(a) é uma pessoa agradável de se ter por perto".

Embora as mulheres entrevistadas tenham relatado satisfação com todos os itens do ISP, verifica-se que as situações relacionadas aos domínios de educação e de confiança, foram as que obtiveram as menores médias. Como exemplo, algumas das situações foram: "Quando eu preci- 
so conversar com alguém, eu posso contar meus problemas ao(a) enfermeiro(a)"; "Eu gostaria que o(a) enfermeiro(a) me desse mais informações sobre os resultados do meu exame" e, "O(A) enfermeiro(a) deveria ser mais atencioso(a) do que ele ou ela é".

Um estudo sobre a representação social da puérpera no $\mathrm{AC}$ mostrou que receber auxílio para o atendimento de suas necessidades básicas e para iniciar sua relação com o seu filho representa segurança, tranquilidade e amparo para a mulher. ${ }^{11}$ Embora a literatura não disponha de estudos que avaliem especificamente a satisfação da puérpera com os cuidados de enfermagem, é possível constatar, nos estudos que avaliam a satisfação de forma geral, que os aspectos relacionados à comunicação e à confiança são muito valorizados pelos clientes. ${ }^{19,21}$ Esses achados são importantes para que o enfermeiro possa reavaliar e planejar as ações educativas que envolvem o cuidado à puérpera, bem como preparar a equipe sobre a importância do relacionamento de confiança entre cliente e equipe.

A confiabilidade do ISP indicou consistência interna satisfatória para o total de itens e para todos os domínios do ISP. Embora não seja possível comparar este estudo com outros que abordam a satisfação da puérpera, estes achados assemelhamse aos de outros estudos que avaliaram a satisfação do paciente adulto. ${ }^{12-13}$

Os dados apontaram diferenças estatísticas em relação ao nível de satisfação das puérperas quanto ao número de gestações e tipo de parto. As mulheres com três ou mais gestações apresentaram maior nível de satisfação para o domínio educacional em relação às mulheres com duas gestações. Uma das possíveis interpretações para esses achados deve-se ao fato de que a experiência adquirida em gestações pregressas permitiu maior conhecimento da puérpera sobre as demandas de cuidado inerentes ao puerpério e aos cuidados com o recém-nascido. Estudos enfatizam que as mulheres que relataram satisfação com o trabalho de parto e nascimento foram aquelas que já tinham uma expectativa prévia sobre seu desempenho durante o parto e também participaram de atividades educativas que as ajudaram a esclarecer quanto ao que esperar desse momento. ${ }^{4} \mathrm{O}$ foco do presente estudo foi avaliar a satisfação no puerpério imediato, que corresponde aos primeiros dez dias após o parto, havendo portanto, a necessidade de estudos que avaliem o nível de satisfação da puérpera nas outras fases do puerpério.
Por outro lado, as mulheres que vivenciaram o parto vaginal relataram maior nível de satisfação comparado ao das mulheres de parto cesáreo, abrangendo tanto situações do domínio educacional como do domínio técnico-profissional. Uma das razões para esses achados pode estar relacionada ao próprio processo de recuperação da puérpera que passou por uma cesárea, procedimento associado a um maior nível de dor e limitação do autocuidado. Em um estudo com mulheres que vivenciaram o parto normal, a percepção do controle pessoal no momento do parto e nascimento foi um fator de satisfação para elas. ${ }^{4}$ Os dados sugerem que as puérperas de pós-cesárea têm outras necessidades, que não vem sendo contempladas adequadamente pela enfermagem.

A puérpera que confia e conhece a função do profissional que lhe presta assistência sabe o que pode esperar desse profissional e deposita nele suas expectativas quanto à sua recuperação. Estudos enfatizam que a melhor compreensão dos cuidados de enfermagem recebidos poderá levar a uma recuperação mais rápida no pós-parto. Os cuidados são baseados na comunicação e no desenvolvimento de objetivos comuns entre paciente e profissional e devem contemplar desde o alívio da dor até a relação de confiança entre eles - fatores que contribuem para gerar maior satisfação. ${ }^{1}$

Desse modo, dentro do objetivo de proporcionar o bem-estar da puérpera, buscando alternativas para que sua recuperação no pós-parto ocorra da melhor maneira possível, todo cuidado se baseia numa boa relação entre enfermagem e paciente, para que a primeira possa interferir prontamente sempre que houver necessidade. Os dados deste estudo sugerem que as demandas de cuidado da puérpera que se recupera de um parto cirúrgico sejam diferentes daquela que se recupera de um parto vaginal. Neste sentido, sugere-se uma reflexão quanto aos cuidados prestados à mulher que se submeteu a uma cesárea, com vias a satisfazer suas necessidades, mas sempre buscando contemplar os objetivos da unidade de $\mathrm{AC}$, que envolve o autocuidado e o cuidado ao recém-nascido.

\section{CONCLUSÕES}

Embora o ISP não seja um instrumento específico para avaliar a satisfação da puérpera durante a sua internação no AC, o seu uso possibilitou mensurar a satisfação com os cuidados de enfermagem. 
As puérperas relataram satisfação com os cuidados recebidos para todos os itens do ISP, cujas médias foram superiores a três pontos, numa escala de um a cinco pontos. As três situações com as maiores médias estiveram presentes nos domínios técnico-profissional e confiança. As três situações com menores médias estiveram presentes nos domínios confiança e educacional.

As puérperas que realizaram parto vaginal julgaram maior nível de satisfação para os domínios educacional e técnico-profissional em relação as mulheres com parto cesáreo e, àquelas com mais de três filhos se mostraram mais satisfeitas quando comparadas às mulheres com dois filhos no que se diz respeito ao domínio educacional, sendo esta uma diferença significativa.

Esses achados podem contribuir para se repensar o cuidado prestado às puérperas em suas particularidades e na diversidade de situações em que se encontra. Ao mesmo tempo em que se deve buscar alcançar os objetivos da unidade, a enfermagem deve também proporcionar um cuidado que esteja de acordo com a demanda de cada paciente, respeitando as limitações e necessidades de cada uma. Esta demanda, segundo os achados deste estudo, aponta para traços do enfermeiro que vão além da sua capacidade profissional técnica, enfatizando o seu aspecto educador e, principalmente, o humanístico.

\section{REFERÊNCIAS}

1. Perla L. Patient compliance and satisfaction with nursing care during delivery and recovery. J Nurs Care Qual. 2002 Jan; 16(2):60-6.

2. Merkouris A, Ifantopoulos J, Lanara V, Lemonidou C. Patient satisfaction: a key concept for evaluating and improving nursing services. J Nurs Manag. 1999 Jan; 7(1):19-28.

3. Janssem BM, Wiegers TA. Strengths and weaknesses of midwifery care from the perspective of women. Evid Based Midwifery. 2006 Oct; 4(2):53-9.

4. Goodman P, Mackey MC, Tavakoli AS. Factors related to childbirth satisfaction. J Adv Nurs. 2004 Apr; 46(2):212-9.

5. Linder-PelzS. Toward a theory of patient satisfaction. Soc Sci Med. 1982 Jul; 16(5):577-82.

6. Risser NL. Development of an instrument to measure patient satisfaction with nurses and nursing care in primary care settings. Nurs Res. 1975 Jan-Feb; 24(1):45-52.

7. La Monica EL, Oberst MT, Madea AR, Wolf RM. Development of a patient satisfaction scale. Res Nurs Health. 1986 Mar; 9(1):43-50.
8. Larrabee JH, Bolden LV. Defining patient-perceived quality of nursing care. J. Nurs Care Qual. 2001 Oct; 16(1):34-60.

9. Peterson WE, Charles C, DiCenso A, Sword W. The newcastle satisfaction with nursing scales: a valid measure of maternal satisfaction with inpatient postpartum nursing care. J Adv Nurs. 2005 Dec; 52(6):672-81.

10. Ministério da Saúde (BR). Portaria 1016 de 26 de agosto de 1993. Dispõe sobre as normas básicas de alojamento conjunto. [documento na internet]. 1996 [acesso 2009 Jul 27]. Disponível em: http:/ / pnass. datasus.gov.br/documentos/normas/40.pdf.

11. Soares AVN, Silva IA. Representações de puérperas sobre o sistema alojamento conjunto: do abandono ao acolhimento. Rev Esc Enferm USP. 2003 Jun; 37(2):72-80.

12. Hinshaw AS, Atwood JR. A patient satisfaction instrument: precision by replication. Nurs Res. 1982 May-Jun; 31(3):170-5.

13. Oliveira AML. Satisfação do paciente com os cuidados de enfermagem: adaptação cultural e validação do Patient Satisfaction Instrument. [dissertação]. Campinas (SP): Universidade Estadual de Campinas, Faculdade de Ciências Médicas; 2004.

14. Pereira JCR. Análise de dados qualitativos: estratégias metodológicas para as ciências da saúde, humanas e sociais. $3^{\mathrm{a}}$ ed. São Paulo (SP): EDUSP; 2001.

15. Montgomery DC, Peck EA. Introduction to linear regression analysis. New York (US): John Wiley \& Sons; 1982.

16. Instituto Brasileiro de Geografia e Estatística (IBGE). Ministério do planejamento, orçamento e gestão. O perfil da mulher jovem de 15 a 24 anos, características diferenciais de desafios [documento na internet] 2000. [acesso 2007 Dez 03] Disponível em: http:// www.ibge.gov.br/home/estatistica/populacao/ populacao_jovem_brasil/comentario2.pdf

17. Morales-Mann ET. Comparative analysis of the perceptions of patients and nurses about the importance of nursing activities in a postpartum unit. J Adv Nurs. 1989 Jun; 14(6):478-84

18. Rudman A, Waldenstöm U. Critical views on postpartum care expressed by new mothers. BMC Health Serv Res. 2007 Nov; 7:178.

19. Queiroz MVO, Jorge MSB, Marques JF, Cavalcante AM, Moreira KAP. Indicadores de qualidade da assistência ao nascimento baseados na satisfação de puérperas. Texto Contexto Enferm. 2007 Jul-Set; 16(3):479-87.

20. Ministério da Saúde (BR). Cirurgia cesariana pode trazer mais complicações e uma pior recuperação pós-parto [documento na internet] Brasília (DF): MS; 2007 [acesso 2007 Dez 06]. Disponível em: http:// portal.saude.gov.br/saude/visualizar_texto. cfm?idtxt=20911. 
21. Mendes ACG, Araújo Junior JLCA, Furtado BMAS, Duarte PO, Santiago, RF, Costa TR. Avaliação da satisfação dos usuários com a qualidade do atendimento nas grandes emergências do Recife, Pernambuco, Brasil. Rev Bras Saúde Matern Infant. 2009 Apr-Jun; 9(2):157-65.

E-mail: guirar@fcm.unicamp.br 